\title{
The European Physical Society and Scientific Freedom
}

\author{
A.R. Mackintosh \\ University of Copenhagen
}

The Cecil Powell Medal given to the Powell Memorial Lecturer at the EPS General Conference. The Lecturer, established in 1975 . discusses the relations between science and society to honour the memory of Cecil Frank Powell, the Nobel Laureate from the University of Bristol who was the President of the World Federation of Scientific Workers.

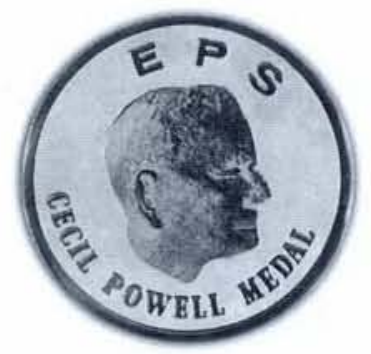

Former Presidents of EPS at a celebration in Pisa in 1988 to mark the Society's 20th anniversary. From the left, R.A. Ricci (1988-91), H.B.G. Casimir (1972-76), G.H. Stafford (1984-86), G. Bernardini (1968-70), A.R. Mackintosh (198082), W. Buckel (1986-88). Not present were E.G. Rudberg (197072) who died in 1980 , I. Ursu $(1976-78)$, J. Friedel (1982-84) and M. Jacob (1991-93),

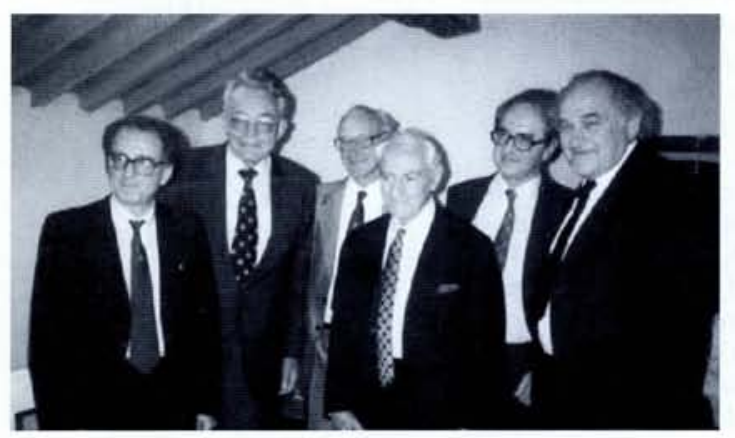

The momentous events of the late-1980's in eastern Europe have given the EPS an opportunity to fulfil one of its most important tasks; the support of physics in parts of the Continent where the scientific enterprise is inhibited by difficult circumstances. Simultaneously, one of the most persistent sources of friction in the life of the Society has been largely eliminated; the obligation to protest and attempt to ameliorate persistent violations of human rights by the governments of some of the members. This contribution is an attempt briefly to summarize the involvement of the EPS in issues of scientific freedom in Europe, and to outline the way in which it has managed to tread the narrow path between indifference and disintegration.

From the beginning, the EPS was envisaged as a pan-European organization, and the rôle of the Eastern countries rapidly gave rise to difficulties. The planning stage was placed in the hands of a Steering Committee, and the most active representative from eastern Europe was Frantisek Janouch, who recalls below the critical events. It was inevitable that a man of Janouch's independence of mind, liberal principles, and personal courage would fall foul of the hard-line communist dictatorship that took over in Czechoslovakia after the 1968 invasion. The Czechoslovakian authorities were left in no doubt about the opinion of the physics community, in both western and eastern Europe, on their treatment of Janouch and it was perhaps partly a consequence of this that he was allowed to emigrate.

\section{The Sakharov Question}

A constructive and relatively peaceful period in the history of the Society ensued after Council decided to transfer the 1975 General Conference to Bucharest. It was abruptly broken by the decision of the Soviet government, early in 1980 , to commit A.D. Sakharov to "internal exile" in Gorki. This event coincided with my appointment as EPS President, and indeed at the Council meeting in Budapest where I was elected, the matter was forcefully raised by Cyril Hilsum. As reported in Europhysics News (April 1980): "A delegate from the Soviet Union made a statement informing Council that the Academy of Science is taking steps to ensure that Academician Sakharov is in a position to continue his work in collaboration with his colleagues in the Lebedev Physical Institute of which he is a scientific staff member." The only problem with this statement was that, as is now well known, it was rather far from the truth. Soon after the meeting, the EPS secretariat received a telegram from the Soviet authorities demanding the replacement of the agreed statement in the minutes by another one which, although presumably closer to the truth, bore little relationship to what had actually been said. Consequently, I declined to accept the revised version.

I must admit that this development rather caught me by surprise. I was, of course, aware of the delicate balance between holding the Society together and exerting pressure on behalf of individual physicists who were being persecuted by their governments, but this had not given rise to significant difficulties during my previous years on the Executive Committee. Nor was I without other problems and aspirations. The EPS was passing through one of its periodic financial crises, Europhysics Letters and the European Journal of Physics were in the planning and launching process, and I was anxious to intensify our collaboration with other societies, especially The American Physical Society. However, our membership obviously expected an attempt by the Society to influence the Soviet authorities to treat Sakharov more humanely, and I therefore wrote several letters to the Academy, without receiving any replies. At the same time, a number of protests were being received about the treatment of other physicists, especially in the USSR, and I decided that it was necessary for the EPS to have a more effective and formalized procedure for dealing with such cases. Accordingly, I recommended to Council the creation of a new Advisory Committee on Scientific Freedom, with the remit to investigate infringements of the scientific and human rights of physicists, and to recommend appropriate action to the President and Executive. This suggestion was accepted at the Council meeting of March 1981, and John Charap, who had demonstrated a strong commitment to such matters, was appointed Chairman. As it transpired, he chaired the committee during the whole of its existence, and his tireless efforts to help physicists from a number of countries to avoid persecution by their authorities were increasingly appreciated.

\section{The Istanbul General Conference}

Further difficulties arose in connection with the EPS-5 General Conference in Istanbul, which had been under preparation for some time. The progressive breakdown of the democratic system in Turkey around 1980 caused the military to intervene and, by the time of the conference in early September 1981, they had taken over the running of the country. The Council decided not to cancel or attempt to move the conference, no doubt recalling that many EPS conferences had been held in countries which could quite justifiably be called military dictatorships, but there were a number of protests from individual physicists and a few cancelled their participation. During the conference, political questions were not particularly prominent, but I did remind our hosts of the advantages of 
democracy on the occasions when I was called upon to make a speech, using a formulation something like I included in my preface to the conference proceedings: "The strains to which the democratic system have recently been subjected by political extremism have been observed with deep concern throughout the world. There is widespread sympathy for the efforts which are being made to overcome these difficulties, combined with the hope and belief that the necessary measures can be taken without seriously compromising the principles of justice and democracy which are characteristic of modern Turkey." The Scientific Freedom Committee dealt effectively and diplomatically with the case of a physicist who had been arrested and detained without trial, and she was soon released. As is well known, Turkey soon made a very welcome return to democracy.

There was one bizarre incident in connection with the Istanbul conference. A group of Turkish academics, not, so far as I know including any physicists, had recently published a report claiming that Turkey had not had any responsibility for the Armenian massacres of 1915. This so enraged a small number of physicists that they decided to boycott the conference. I had little sympathy with this action, burdened as I was by what I regarded as more pressing problems. The Armenian massacres were, of course, abominable, and it is important that the responsibility for their perpetration be historically placed, but intercourse between scholars of different nations would be impossible if it depended on agreement on the interpretation of distant history.

\section{Sakharov Again}

More serious was the development in the situation of Sakharov, which was the subject of a sometimes acrimonious debate at the Council meeting at the Istanbul conference. The Soviet authorities refused to allow him, and another Soviet physicist, to participate at the 10th European Conference on Controlled Fusion and Plasma Physics in Moscow in mid-September and, soon afterwards, he and his wife began a hunger strike in protest against the refusal to grant an exit visa to their daughter-in-law. The potential consequences of this development alarmed me greatly and, at the beginning of December, I sent a telegram to the President of the Soviet Academy of Sciences in which I expressed my concern on behalf of the EPS and requested him "to appeal to the Soviet government to act in a humanitarian way to cause Sakharov to abandon his hunger strike." The storm of protest from the whole world caused the Soviet authorities to back down and grant the required exit visa, with the result that the hunger strike was discontinued.

True to tradition, I received no response from the President of the Soviet Academy to my telegram. However, in March 1982 he sent me a statement from the National Committee of Soviet Physicists against nuclear weapons, containing the sentence: "We resolutely protest against the deployment of new nuclear missiles in Europe" (no mention was made of the old ones), with the suggestion that the EPS should adopt it and send it to the United Nations General Assembly on Disarmament. I regarded this initiative as a rather unsubtle piece of political propaganda and, on the recommendation of the Executive, Council decided not to act upon it. A much more balanced statement was, however, later drafted by the EPS Advisory Committee on

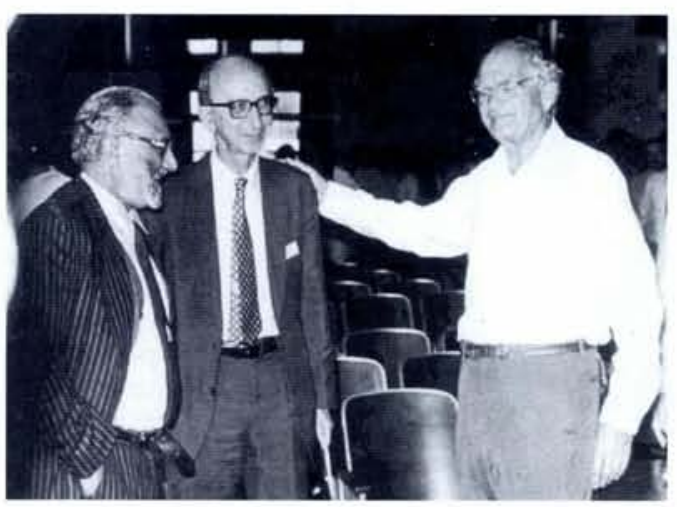

A. Salam, E. Inönü, and V.F. Weisskopf (from the left) at the fifth EPS General Conference Trends in Physics in Istanbul in September 1981. Professor Inönü, a leading Turkish politician, President of the Turkish Physical Society, and Chairman of the conference, was from Boğaziçi University that hosted the meeting.

Physics and Society and sent to the representatives of the USA and the USSR in Geneva.

\section{The Prague General Conference}

When I retired as EPS President in 1982, I hoped that the Society had learned to live with the difficult issue of scientific freedom, but fate had one more major tribulation in store. In accordance with the tradition of periodically placing the General Conference in eastern Europe (Istanbul was, ignoring geography, counted as western Europe), it was decided to hold the next meeting in Prague in August 1984. Prior to this decision, I had visited Prague and received assurances from the President of the Czechoslovak Academy, and from the local organizers, that there would be no restriction on attendance at the conference. These assurances, which I believe were given in good faith, were repeated to the Council before it formally accepted the invitation and, for example, Israeli physicists were indeed able to attend. However, as Janouch describes below, his visa to attend the conference was refused on the grounds that he had been deprived of citizenship under Czechoslovakian law. In the ensuing controversy, principles, practicalities and legalities became inextricably entwined. In the end, it was decided, under protest, to proceed with the conference and the Council Meeting, but a number of individuals declined as a matter of principle to attend. In his letter to John Ziman, attempting to justify the exclusion of Janouch, the President of the Czechoslovak Academy accused the latter of "actively working against the interests of our country". This was perhaps the crux of the matter. What he should have written, of course, was "actively working against the interests of the Communist government of our country". The extent to which these two sets of interests coincided was decided by the Czechoslovakian people a few years later.

\section{The Death Throes and its Aftermath}

After the Prague meeting, there were no further major incidents, although the death throes of the communist system in eastern Europe produced a number of cases in which the Advisory Committee on Scientific Freedom and the EPS Executive intervened on behalf of persecuted physicists. There were also occasional problems in other regions.

In 1988, for example, the deportation of a physicist from the Territories of the West Bank occupied by Israel was investigated, with

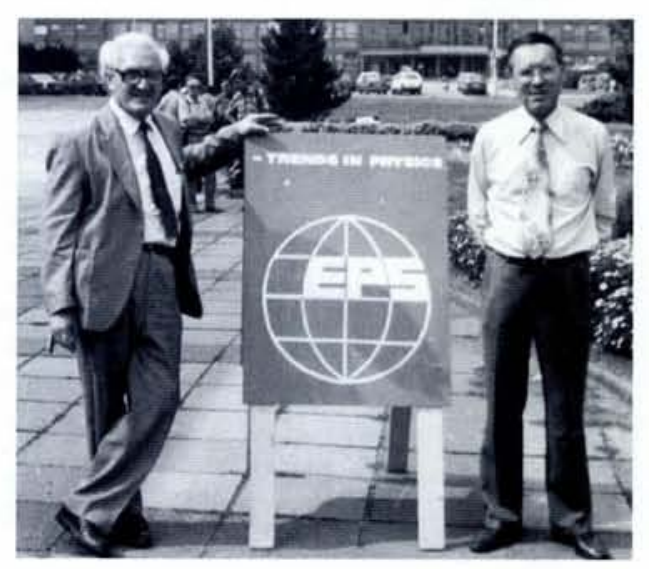

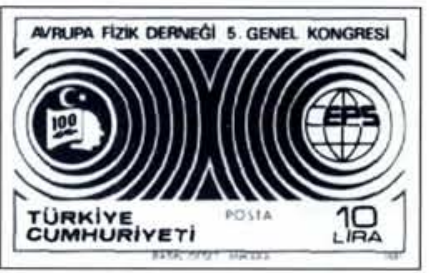

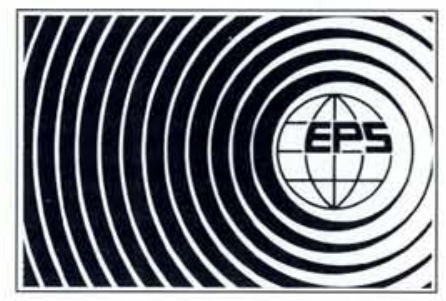

A stamp (upper) issued in Istanbul to commemorate EPS-5. The motive was adopted as the logo (lower) for EPS General Conferences.
Jan Kaczér, on the left, and Štefan Zajec, Chairman and Secretary, respectively, of the Local Organizing Committeee for the 6th General Conference in Prague in September 1984. The EPS logo was designed in Prague at the time the Society operated a Branch Secretariat in the Institute of Physics. 


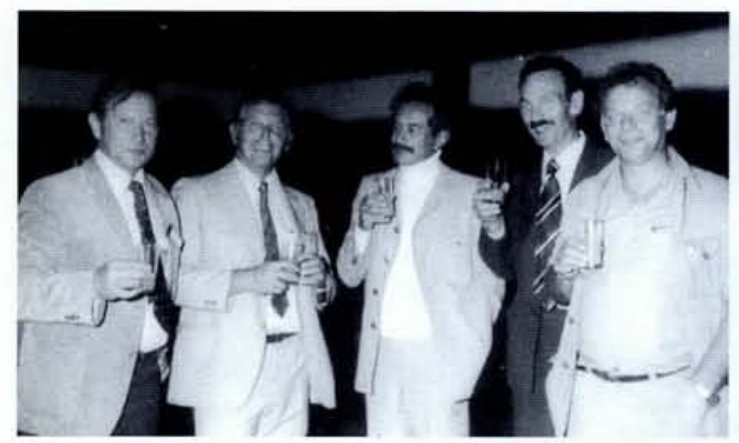

the co-operation of the Israeli Physical Society. By 1989, such incidents had become sufficiently infrequent that the Executive Committee decided to dissolve the scientific freedom committee, and Charap was appointed to the Advisory Committee on Physics and Society, with special responsibility for questions of scientific freedom. Since he is also a member of the At the EPS-5 General Conference in Istanbul: from the left, A.B. Berezin from Leningrad (now St. Petersburg), W.J. Merz (Chairman of the Conference Committee, 1976-82, and EPS Secretary. 1983-89) from the RCA Laboratories in Zurich, J.M. Charap, a turkish politician, and Zh.I. Alferov from the Joffe Institute in Leningrad. was never any question over persecuted physicists in any part of Europe, or indeed further afield, being given support; the dilemma lay in the extent of this support. Dictatorships of any kind are rarely sensitive to ethical considerations, but they may be sufficiently pragmatic to act in a humane fashion when they perceive it to be in their own interest. The communist governments of eastern Europe were interested in maintaining scientific contacts with the rest of the world, largely in the hope of propping up their disintegrating economic systems, and were willing to pay a price for doing so. This price could not, however, be set too high. In retrospect, it is clear that the EPS came close to fission in the cases of both Janouch and Sakharov, but by remaining intact, the Society was able to help them more than a more uncompromising condemnation of their persecutors would have allowed. We did not experience many examples, either by the Society or by individual physicists, of the self-indulgent protest whose principal consequence is to induce a feeling of moral superiority on the part of the protagonist. I believe that the leadership of the EPS generally acted wisely in not cancelling conferences and other functions, even though they were sometimes sorely provoked. On the other hand, the protests and boycotts by individuals were in many cases appropriate and useful in representing the indignation of the physics community.

I cannot recall any physicist who behaved in a blatantly opportunistic manner or without ethical scruples during these difficult years. Some of us in the West may have shown too little understanding of the problems of our eastern colleagues, a small number of whom may have given their career priority over their human obligations, but there was always a feeling, mostly expressed in private, that we were all on the same side. The contact and understanding which was maintained between individuals and societies through severe stresses has placed the EPS in an ideal position to play its essential rôle in strengthening physics throughout the whole of the continent in the future.

\section{Ensuring East European Participation}

\section{F. Janouch recalls many of the difficulties.}

A photograph taken in 1982 of the Institute of Physics of the Czechoslovak Academy of Sciences that housed the EPS Branch Secretariat. The Institute belonged to the Academy's main complex on Na Slovance on the outskirts of Prague.

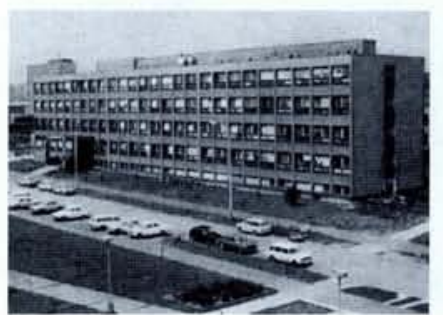

Although the second half of the 1960's was a relatively liberal period in the Soviet bloc, it was not obvious that the various countries would join the moves to form EPS, as this depended on high-level decisions taken in the Soviet Union. It was also clear that EPS would be less attractive if physicists from eastern Europe were not involved. Their participation in the Steering Committee formed in 1966 was rather sporadic, and only three were present at the Committee's third meeting in January 1968, although all national societies and academies had been invited (for the first time). Jan Tauc was appointed to represent the Czechoslovak Academy of Sciences in early 1968, and I was informed at about the same time of the plans to establish EPS. We both became enthusiastic supporters, and I was co-opted in March to the Bureau of the Steering Committee.

While the political atmosphere allowed Czechoslovakian physicists to play an active rôle, it was clear that money was an obstacle since access to hard currencies was restricted. Accordingly, some of us invited the Committee to meet in Prague in May 1968. Behind the scenes efforts by the Czechoslovak Academy of Sciences to persuade academies and national physical societies from the Soviet bloc to send delegates were successful (20 attended, and only Bulgaria was not represented).

There was a separate meeting of the east European contingent where a joint policy towards the EPS should have been worked out. Various attitudes were expressed and in the main, the idea of an EPS was strongly supported, physicists correlating its creation with the opening up of contacts with western Europe. For some delegates, the concept that individuals could become members of an international society seemed strange, contradicting the rules governing relations with foreign organizations; they preferred an umbrella association. For the Soviet Union, 